\title{
Lignocellulosic Analysis of Corncob Biomass by Using Non-Thermal Pulsed Electric Field-NaOH Pretreatment
}

\author{
A W Putranto ${ }^{1, *}$, S H Abida ${ }^{2}, \mathrm{~K}$ Adrebi ${ }^{2}$ \\ ${ }^{1}$ Bioprocess Engineering, University of Brawijaya, Malang, Indonesia \\ ${ }^{2}$ Biotechnology, University of Brawijaya, Malang, Indonesia \\ *Corresponding author. Email: angkywahyu@ub.ac.id
}

\begin{abstract}
In recent years, the second-generation bioethanol and advanced bio-based material production from biomass are focused on the pretreatment process by separating cellulose components from other components such as lignin and hemicellulose. Therefore, a physicochemical pretreatment method is needed by applying non-thermal pulsed electric field (PEF) and alkali methods to increase the cellulose availabilities with a short process and low energy input. The aim of this study was to analyze the lignocellulose content of corncob biomass by using non-thermal pulsed electric fields (PEF) and NaOHpretreatment. The pretreatment factors used were the electric field strength of PEF and the pretreatment time. Analysis of the structure and elements of the lignocellulose based on the characteristics of the gravimetric method and SEM-EDX for control and treated samples. The results showed that pretreatment of corncobs biomass by using PEF optimally at an electric field strength of $9 \mathrm{kV} / \mathrm{cm}$ and pretreatment time of 60 seconds that was increasing cellulose of $40.59 \%$ when compared with the control and also decreasing the hemicellulose and lignin content of $12.9 \%$ and $2.02 \%$, respectively. Under these conditions, the energy per pulse and specific input energy of PEF required $0.0205 \mathrm{~J}$ and $8.72 \mathrm{~kJ} / \mathrm{L}$, respectively. The microstructure analysis by using SEM-EDX showed significantly visual differences and was an increase in the percentage of $\mathrm{C}$ and $\mathrm{O}$ atoms between untreated and treated samples. Furthermore, the corncob biomass treated by using non-thermal PEF and alkali can effective and efficient for the next process into cellulose-derived products.
\end{abstract}

Keywords: Corncob biomass, Pulsed electric field, NaOH, Cellulose

\section{INTRODUCTION}

The use of biomass as the main resource for the production of second-generation bioethanol and subsequent conversion processes into advanced biomaterials has become the main focus of several countries in the world. Lignocellulose as an alternative raw material for bioethanol has advantages such as low energy, abundant availability, low cost, and higher bioethanol yield. Thus, the utilization of biomass waste has been projected in sustainable development to help reduce deforestation by reducing our dependence on forest woody biomass to produce biofuels [1]. The problem that arises in the process of converting biomass feedstock into biofuel lies in the cell wall of biomass which has an integral structural complexity of the lignocellulose fraction and as a strong barrier of inhibitors and by-products produced during pretreatment [2].
Therefore lignocellulosic binding structure consisting of cellulose, hemicellulose, and lignin must be broken down. Also the lignin content must be removed through the pretreatment process. In general, the stages in the biomass pretreatment process include the process of damaging hydrogen bonds in crystalline cellulose, then the process of breaking the matrix of hemicellulose and lignin, and the final process is increasing porosity and surface area of cellulose for subsequent enzymatic hydrolysis [3]. Some criteria to be considered in choosing a pretreatment method include low energy costs, the inlvolvement of pretreatment catalysts with low processing costs, efficient processing time which can later have an impact on the downstream process stages and commercialization related to operating costs, capital costs and biomass costs [2]. Therefore, the application 
of appropriate pretreatment methods for the deconstruction of cell wall structures during the conversion process is also a matter of concern.

The application of non-thermal Pulsed Electric Field (PEF) technology with low electric field strengths between $5-20 \mathrm{kV} / \mathrm{cm}$ with a short time can damage the cellulose bonds to other sugar groups/elements and cause the separation of lignocellulose bonds [2]. The advantage of using PEF is that it is very short on time, low power requirements and simple instrument design [4]. However, the use of PEF in the pretreatment process must also consider the electric field strength and pretreatment time since it is closely related to the

\section{MATERIALS AND METHODS}

\subsection{Apparatus and materials}

The main apparatus used in this study is a laboratory-scale PEF and the installation scheme represented in Figure 1. The treatment chamber of PEF has a maximum capacity of $13 \mathrm{~L}$ made from stainless steel which is safe and resistant to alkaline or acidic chemicals. Negative and positive electrodes installed in the treatment chamber are also made of stainless steel with a distance between the electrodes of $3.25 \mathrm{~cm}$. The energy needed by the PEF during the pretreatment process. The aim of this study was to analyze the lignocellulose content of corncob biomass by using non-thermal PEF and alkali pretreatment. Corncob biomass waste was chosen not only because of its suboptimal utilization but also has a high cellulose content compared to other biomass wastes [4]. It is expected that the non-thermal pretreatment process using PEF and $\mathrm{NaOH}$ can effectively and efficiently reduce lignin and hemicellulose and increase cellulose content in corncob biomass. Hence it can support the production of second-generation bioethanol and subsequent conversion processes into several other advanced biomaterial products.

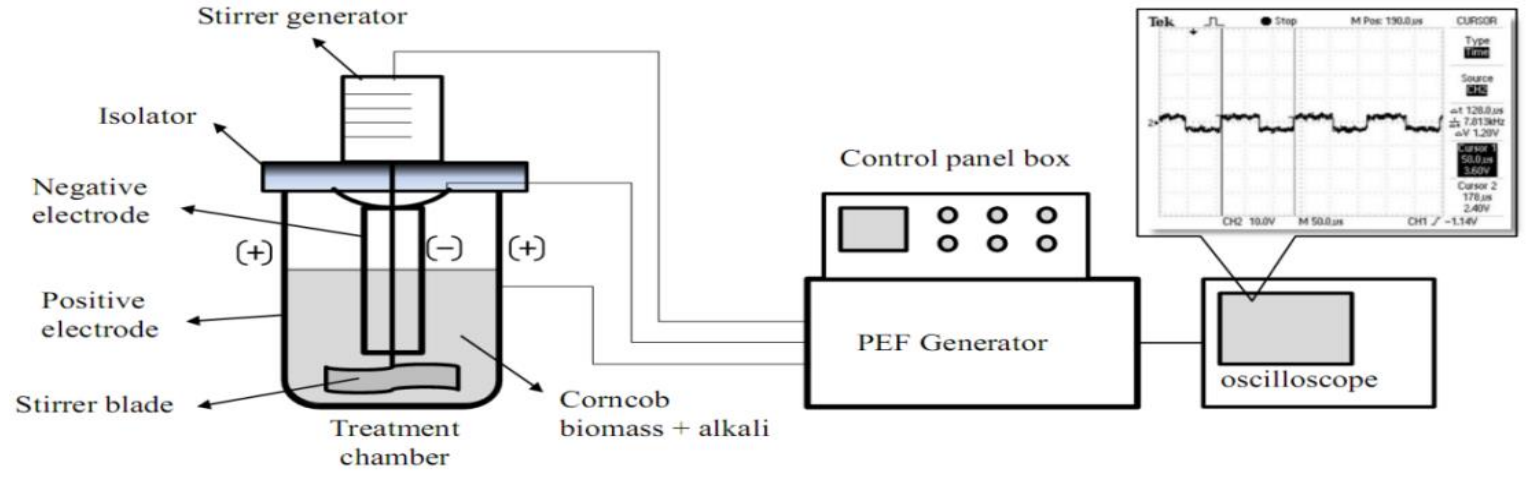

Figure 1 Pulsed electric field installation scheme

PEF generator contains several electronic circuits to produce high-voltage electrical pulses. The control panel provides the power button, speed control button, input voltage regulator, high voltage button, timer (OMRON type H5CX-AN) and input voltage display. The PEF design was modified and adapted to the needs of the corn cob biomass pretreatment process for laboratory scale.
In addition, the PEF apparatus also has been calibrated between the input voltage and the output voltage as shown in Table 1, while the measurement of frequency and pulse width also measurements using an oscilloscope.The PEF apparatus has an output voltage specification between $8-31.36 \mathrm{kV}$, the electric field strength (Ef) produced $2.46-9.65 \mathrm{kV} / \mathrm{cm}$, the input frequency of $7.813 \mathrm{kHz}$, the square pulse generated has a pulse width of $66 \mu$ s, and the stirrer speed of 50-200 rpm. While the materialused in this study was corncobs as biomass waste obtained from farmers in MalangIndonesia,distilled water, $\mathrm{NaOH}$, and $\mathrm{H}_{2} \mathrm{SO}_{4}$ pa (Merck).

Table 1. The voltage calibration in PEF apparatus

\begin{tabular}{|l|r|r|r|r|r|r|r|r|r|r|}
\hline Voltages & \multicolumn{10}{|c|}{ Voltage calibration result } \\
\hline Input voltage $(\mathrm{V})$ & 3.00 & 5.00 & 8.80 & 10.00 & 13.00 & 15.00 & 18.00 & 20.00 & 20.15 & 25.00 \\
\hline Output voltage $(\mathrm{kV})$ & 8.00 & 13.60 & 16.25 & 17.40 & 23.40 & 26.30 & 27.94 & 29.20 & 29.25 & 31.36 \\
\hline Ef $(\mathrm{kV} / \mathrm{cm})$ & 2.46 & 4.18 & 5.00 & 5.35 & 7.20 & 8.09 & 8.60 & 8.98 & 9.00 & 9.65 \\
\hline
\end{tabular}




\subsection{Corncob Pretreatment Process}

Dried corncobs milled and sieved 60 mesh, then added $60 \% \mathrm{NaOH}$ solution with a ratio of $1: 10(\mathrm{w} / \mathrm{v})$ and filled into the treatment chamber. The input voltage of PEF is set to produce electric field strength at 5 and $9 \mathrm{kV} / \mathrm{cm}$ and pretreatment time is set at 60 , 180 and 300 seconds. The stirring process $(100 \mathrm{rpm})$ is carried out during the pretreatment process. Furthermore, corncobs powder mixed with $\mathrm{NaOH}$ from the treatment chamber then filtered and neutralized with distilled water.

\subsection{Analysis Method}

The analysis of cellulose, hemicellulose, and lignin was conducted by using the Chesson method [5].While, the energy needs analysis in this study is based on the energy value per pulse and specific input energy according to the equation below:

\section{RESULT AND DISCUSSION}

\subsection{Lignocellulose Content of Corncob Biomass}

Corncob biomass without treatment and treated by varying the electric field strength and pretreatment time, containing cellulose, hemicellulose, and lignin, as indicated in Table 2. The highest component of corncob biomass (untreated) is hemicellulose (38.32\%), and followed bycellulose content $(22.5 \%)$ and lignin content $(11.72 \%)$. Based on Table 2, it can be seen that the cellulose content of corncob after pretreatment has increased cellulose with a range between $56.63 \pm 2.48 \%-63.09 \pm 1.73 \%$.

The optimum increase incellulose content $(63.09 \pm 1.73 \%)$ carried out at the electric field strength of $9 \mathrm{kV} / \mathrm{cm}$ and pretreatment time of 60 seconds. The increased pretreatment time (up to 300 seconds) on the electric field strength of $9 \mathrm{kV} / \mathrm{cm}$, did not show a significant increase in cellulose and decrease in hemicellulose. However, the difference in the strength of the electric field provided can increase cellulose and at the same time decrease hemicellulose of corncob biomass which is quite significant. Therefore, the electric field strength factor has a major role in the PEF pretreatment process to damage lignocellulosic bonds.
Calculation of energy per pulse $(\mathrm{J})$ :

$$
W_{\text {pulse }}=U x I x \tau
$$

Calculation of specific input energy $(\mathrm{kJ} / \mathrm{L})$ with the equation:

$$
W_{\text {spec }}=\frac{f(t)}{V o l} x W_{\text {pulse }} \tau
$$

Where $W_{\text {pulse }}$ is the energy per pulse $(J), U$ is the PEF voltage $(\mathrm{V}), \mathrm{I}$ is the current $(\mathrm{A})$ and $\tau$ is the pulse width (s). While $\mathrm{W}_{\text {spec }}$ is the specific input energy $(\mathrm{kJ} / \mathrm{L}), \mathrm{f}$ is the frequency $(\mathrm{Hz}), \mathrm{t}$ is the pretreatment time and Vol is the volume of material inside the treatment chamber (L). The microstructure analysis was carried out with the principle of visual image detection through scanning electron microscopy (FEI Inspect S50 Genesis). Microstructure analysis using SEM is equipped with EDX-EDAX analysis which is used to evaluate morphological changes and elements analysis of untreated and treated samples.

A significant increase in cellulose content between untreated and treated samples proved that the pretreatment method using non-thermal PEF and $\mathrm{NaOH}$ was able to increase the cellulose content of corncob biomass. The electric field strength that is exposed to the surface of corncob biomass aims to damage the structure of hydrogen bonds that connects lignin-hemicellulose and lignin-cellulose so that the lignocellulosic bonding structure undergoes irreversible termination. In such conditions, $\mathrm{NaOH}$ added during the pretreatment process will easily dissolve lignin and hemicellulose and other amorphous particles. The phenomenon of breaking hydrogen bonds together with alkali dissolution processes can also change the cellulose crystal structure and produce better cellulose chains [6]. In addition, the reduced content of lignin, hemicellulose, and other particles will increase the degree of crystallinity of cellulose. The crystallinity index also increases with increasing crystal size because the surface of the crystal corresponds to the reduction of amorphous particles that protect cellulose [7]. On the other hand,the higher crystallinity index of cellulose also has great potential to produce micro crystalline cellulose (MCC) or even become nano crystalline cellulose (NCC), bioplastics and other derivative products. 
Table 2. The lignocellulose content of corncob biomass on the variation of electric field strength and pretreatment time

\begin{tabular}{|c|c|c|c|c|}
\hline \multicolumn{2}{|c|}{ Pretreatment variables } & \multicolumn{3}{c|}{ Lignocellulose content } \\
\hline \multirow{2}{*}{ Ef(kV/cm) } & Pretreatment time (second) & Cellulose (\%) & Hemicellulose (\%) & Lignin (\%) \\
\hline Untreated samples & 22.50 & 38.32 & 11.72 \\
\hline \multirow{3}{*}{5} & 60 & $59.84 \pm 0.11$ & $28.58 \pm 1.48$ & $9.61 \pm 0.54$ \\
\cline { 2 - 5 } & 180 & $56.63 \pm 2.48$ & $30.17 \pm 2.81$ & $9.54 \pm 0.09$ \\
\cline { 2 - 5 } & 300 & $61.21 \pm 0.43$ & $28.41 \pm 0.29$ & $9.80 \pm 0.12$ \\
\hline \multirow{3}{*}{9} & 60 & $63.09 \pm 1.73$ & $25.42 \pm 0.66$ & $9.69 \pm 1.21$ \\
\cline { 2 - 5 } & 180 & $62.76 \pm 0.08$ & $25.91 \pm 0.22$ & $9.32 \pm 0.16$ \\
\cline { 2 - 5 } & 300 & $62.64 \pm 0.53$ & $26.03 \pm 0.39$ & $9.97 \pm 0.09$ \\
\hline
\end{tabular}

Hemicellulose is a compound that makes up plant cell walls together with cellulose and lignin. Table 2 shows the hemicellulose content of corncob biomass has decreased $12.9 \%$ when compared with untreated samples. The highest decrease in hemicellulose content occurred in the variation of electric field strength treatment $9 \mathrm{kV} / \mathrm{cm}$ and pretreatment time of 60 seconds. It is also the same as the PEF treatment to produce the highest increase in cellulose.

Therefore, there is a correlation between reducing hemicellulose content and increasing cellulose content. Hemicellulose has characteristics that are relatively sensitive to operating conditions. Although in this study the variation of pretreatment time did not have a significant effect, but the pretreatment time had to be controlled to avoid the formation of undesirable products such as furfurals and hydroxymethyl furfurals which could later inhibit the subsequent downstream process, like the fermentation process [8].

Lignin is a component that protects cellulose in plant cell walls. One of the main objectives in the biomass pretreatment process is delignification or reduction in lignin content which will be accompanied by an increase in cellulose in corncob biomass. In addition, another purpose of delignifica-tion is to facilitate the enzymatic saccharification process which

\subsection{Energy Analysis During PEF-alkali Pretreatment}

Analysis of energy requirements during the pretreatment process with PEF is an important parameter in maintaining the characteristics of nonthermal treatment. The energy needed during the treatment process using PEF consists of the calculation of energy per-pulse and specific input energy. Energy is an important parameter in the pretreatment process [3]. Table 2 shows the lignin content decreased between $1.75 \%-2.4 \%$ when compared withuntreated sample.

The highest reduction in lignin content $(9.32 \pm 0.16 \%)$ occurred in the treatment of electric field strength of $9 \mathrm{kV} / \mathrm{cm}$ and pretreatment time of 180 seconds. The physical pretreatment method has a minor effect in reducing lignin[8], therefore an alkaline $\mathrm{NaOH}$ solvent was added to dissolve the lignin structure when high voltage pulses have damaged the hydrogen bond with hemicellulose.

Thealkalinisation pretreatment process using $\mathrm{NaOH}$ has the advantage that it does not require a complex reactor so that it is easy to apply and can be carried out at room temperature [8]. On the other hand, the use of alkaline or acidic solvents in conventional chemical pretreatment still has limitations such as being corrosive, toxic and not in line with the principles of green technology indeed. Therefore it is recommended for the biomass pretreatment process using green solvents that require low pressure, stable at room temperature and non-flammable such as deep eutectic solvent (DES) [9].

per- pulse is the amount of energy given to the series per- pulse magnitude expressed in Joules. The specific input energy is the energy given for each unit volume of material during the pretreatment process with PEF expressed in units of $\mathrm{kJ} / \mathrm{L}$. Based on equations (1) and (2), the energy per-pulse and specific input energy can be calculated which can be seen in Table 3. The energy per- pulse needed by PEF is positively correlated with the output voltage generated, current and pulse width. 
Since the current value used and the pulse width produced by the PEF apparatus are the same, the amount of energy per pulse is determined by the output voltage and the electric field strength ofPEF. However, a high energy per pulse value does not always cause a high mass transfer, but it is also adjusted to the condition of the cell to be treated by
PEF. The total permeabilization of plant cell tissue is obtained by applying either a very high pulse energy or several low energy per pulses[10].Based on Table 3 it can also be seen that the specific input energy needed during the pretreatmentprocess of corncob biomass with $\mathrm{PEF}$ is between $4.84-43.60 \mathrm{~kJ} / \mathrm{L}$.

Table 3. The specific input energy of PEF during the pretreatment process

\begin{tabular}{|c|r|c|c|}
\hline $\begin{array}{c}\text { Electric Field Strength } \\
(\mathrm{kV} / \mathrm{cm})\end{array}$ & $\begin{array}{r}\text { Pretreatment time } \\
\text { (second) }\end{array}$ & $\begin{array}{c}\text { Energy per Pulse } \\
\text { (Joule) }\end{array}$ & $\begin{array}{c}\text { Specific Energy } \\
\text { Input (kJ/L) }\end{array}$ \\
\hline \multirow{2}{*}{5} & 60 & \multirow{2}{*}{0.0114} & 4.84 \\
\cline { 2 - 2 } & 180 & & 14.53 \\
\cline { 2 - 2 } & 300 & \multirow{2}{*}{0.0205} & 24.22 \\
\hline \multirow{2}{*}{9} & 60 & & 8.72 \\
\cline { 2 - 2 } & 180 & & 26.16 \\
\cline { 2 - 2 } & 300 & & 43.60 \\
\hline
\end{tabular}

In this study, the highest specific input energy value $(43.60 \mathrm{~kJ} / \mathrm{L})$ is still relatively low for energy requirements during the biomass pretreatment. When converted to electrical power used, the highest specific input energy PEF is $0.73 \mathrm{kWh}$, while in the best treatment, the electrical energy needed is $0.15 \mathrm{kWh}$. This is also supported by the application of low electric field strength $(9 \mathrm{kV} / \mathrm{cm})$. The higherelectric field strength application (above $35 \mathrm{kV} / \mathrm{cm}$ ) is suitable for bacterial inactivation process, while the application

\subsection{Microstructure and Element Composition Analysis}

The morphological structure of corncob biomass was observed using SEM-EDX to evaluate changes in external structure caused by pretreatment treatment. Corncob biomass with an electric field strength treatment of $9 \mathrm{kV} / \mathrm{cm}$ and 60 seconds of low electric field strength $(1-10 \mathrm{kV} / \mathrm{cm})$ is suitable for increasing mass transfer in the extraction of important antioxidant compounds (carotenoids, phenolics, and anthocyanins) from agricultural materials and biomass pretreatment processes [10][14]. The low specific input energy will certainly also affect cheaper production costs, so the pretreatment process with PEF has the potential to be applied on an industrial scale.

pretreatment time and untreated samples then performed microstructure and element composition testing with SEM-EDX. The electric field strength from PEF have the effect of forming gaps and preferential pathways in the membrane cell structure. This is also evidenced from the SEM results between the untreatedand treated of corncob biomass at $50 \mu \mathrm{m}$ magnification (Figure $2 \mathrm{a}$ ). 


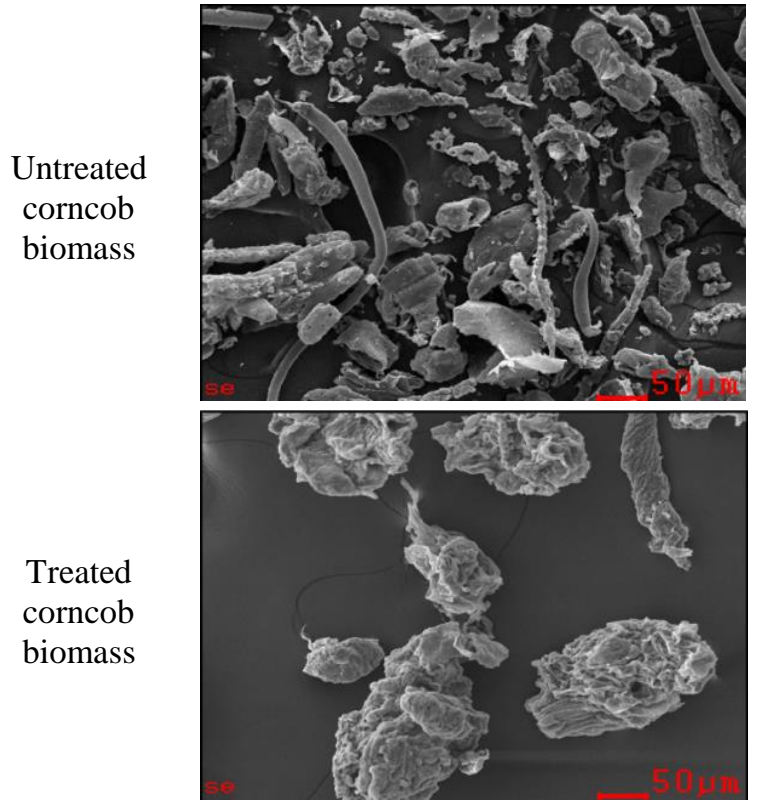

(a)

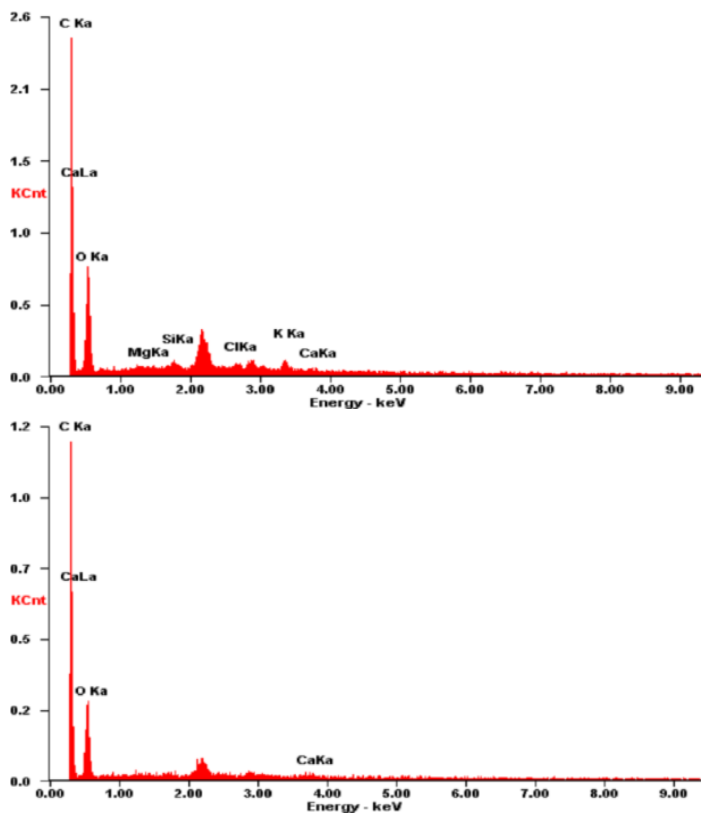

(b)

Figure 2. SEM results of untreatedand treated corncob biomass (Ef of $9 \mathrm{kV} / \mathrm{cm}$ and pretreatment time of 60 seconds) with magnifications of $50 \mu \mathrm{m}$ (a) and SEM-EDX microanalysis(b)

The morphological structure in untreated corncob biomass at various magnifications has a clear visual differences when it was compared with treated by $\mathrm{PEF}-\mathrm{NaOH}$. The structure of corncob biomass has amorphous-looking fibers, many flakes of several types of fiber, and many celluloses which are still in the form of bundles. While, the microstructure of the sample after the pretreatment was seen one type of fiber bundle that could split into single cellulose fiber. This also shows that the non-thermal treatment method of PEF-NaOH can damage the lignocellulosic structure of the biomass and at the same time dissolve amorphous fiber portions so that one component and bundle fibers appear.

The application of high voltage pulses PEF leads to the induction of critical electric potential across the cell membrane, thus causing local structural changes and disruption of cell wall membrane integrity. Increased mass permeability causes pores or cracks that damage the plant's main cell wall. Since plant cell membranes consist of cellulose, hemicellulose, and lignin, the pores that occurs in the primary cell wall due to PEF indirectly also damages the bonds between lignocellulose in biomass. Under these conditions, the
$\mathrm{NaOH}$ solution that is in the treatment chamber can easily get into the macrofibril fiber to carry out the delignification process. In addition, degradation of amorphous cellulose fraction also becomes easier and requires a shorter time.

In this study, a quantitative analysis of changes in microstructure between untreated and treated sample by using SEM-EDX represented in Figure $2 b$ and Table 4. Based on Table 4, the untreated sample of corncob biomass has 5 types of atoms detected, whereas in the pretreated sample (electric field strength of $9 \mathrm{kV} / \mathrm{cm}$ and pretreatment time of 60 second) there are only 3 types of atoms detected namely $\mathrm{C}, \mathrm{O}$, and $\mathrm{Ca}$. The atomic weight of $\mathrm{C}$ in the treatment sample increased from $51.67 \%$ to $56.52 \%$ when compared to untreated sample. While the percentage of the number of $\mathrm{C}$ atoms in the treatment sample also increased from $59.91 \%$ to $63.66 \%$. The weight of $\mathrm{Ca}$ atoms also increased from $0.48 \%$ to $0.86 \%$, with the percentage of the number of $\mathrm{Ca}$ atoms in the treatment sample also increasing from $0.17 \%$ to $0.29 \%$. The presence of several other atoms $(\mathrm{Mg}, \mathrm{Si}$, $\mathrm{Cl}$, and $\mathrm{K}$ ) detected indicates that there are still some other fibers contained in the treated samples. 
Table 4. Percentage of atoms detected using SEM EDX microanalysis

\begin{tabular}{|c|c|c|c|c|}
\hline \multirow{2}{*}{ Atoms } & \multicolumn{2}{|c|}{ Untreated samples } & \multicolumn{2}{c|}{ Pretreated samples } \\
\cline { 2 - 5 } & Weight (\%) & Amount(\%) & Weight (\%) & Amount (\%) \\
\hline $\mathrm{C}$ & 51.67 & 59.91 & 56.52 & 63.66 \\
\hline $\mathrm{O}$ & 43.98 & 38.29 & 42.63 & 36.05 \\
\hline $\mathrm{Mg}$ & 0.54 & 0.31 & - & - \\
\hline $\mathrm{Si}$ & 0.76 & 0.37 & - & - \\
\hline $\mathrm{Cl}$ & 1.00 & 0.39 & - & - \\
\hline $\mathrm{K}$ & 1.58 & 0.56 & - & 0.29 \\
\hline $\mathrm{Ca}$ & 0.48 & 0.17 & 0.86 & \\
\hline
\end{tabular}

The $\mathrm{C}, \mathrm{O}$ and $\mathrm{H}$ atoms are the atoms in the cellulose monomer aldehyde group. However, in this study $\mathrm{H}$ atoms cannot be detected by SEM-EDX due to the very small number of $\mathrm{H}$ atoms or 1 electron. Therefore further research is recommended to use $\mathrm{X}$ Ray Diffraction (XRD) analysis to determine the

\section{CONCLUSION}

The gravimetric analysis and SEM-EDX microanalysis showed that the non-thermal PEF pretreatment method can effectively and efficiently increase the cellulose content of corncob biomass. An electric field strength of $9 \mathrm{kV} / \mathrm{cm}$ and the pretreatment time for 60 seconds shows the highest increase in cellulose content, decreased hemicellulose and lignin content. Under these conditions, low energy is neededduring non-thermal PEF-NaOHpretreatment. The electric field strength of PEF has a significant

\section{REFERENCES}

[1] SainiJ K SainiR and TewariL 2015 Lignocellulosic agriculture wastes as biomass feedstocks for second-generation bioethanol production: concepts and recent developments Biotech5 4 337-353

[2] Kumar A Kand Sharma S 2017 Recent updates on different methods of pretreatment of lignocellulosic feedstocks : a review Bioresour.Technol.4 1 1-19

[3] Li C Knierim B Manisseri C Arora R Scheller H V Auer M Vogel KP Simmons B A Singh S 2010 Comparison of dilute acid and ionic liquid pretreatment of switchgrass :Biomass recalcitrance, delignification and enzymatic saccharificationBioresour.Technol.101 134900 4906 presence of $\mathrm{C}, \mathrm{O}$ and especially $\mathrm{H}$ atoms. However, even though the $\mathrm{H}$ atom is not detected at all in microanalysis using SEM-EDX, the $\mathrm{C}$ and $\mathrm{O}$ atoms increasing both the amount and the weight are the main indicators that the compounds detected in SEMEDX in the treatedsample are cellulose compounds.

influence on the cellulose content of corncob biomass pretreatment. The microstructure analysis by using SEM-EDX showed significantly visual differences and was an increase in the percentage of $\mathrm{C}$ and $\mathrm{O}$ atoms between untreated and treated samples. Furthermore, the corncob biomass treated by using non-thermal PEF and alkali can effective and efficient for the next downstream process as converted into commercial cellulose-derived products.

[4] Kumar P Barrett D M Delwiche M J and Stroeve P 2009 Methods for pretreatment of lignocellulosic biomass for efficient hydrolysis and biofuel production Ind. Eng. Chem. Res. 48 $83713-3729$

[5] Datta R 1981 Acidogenic fermentation of lignocellulose-acid yield and conversion of components Biotechnol. Bioeng.239 2167-2170

[6] Suryanto H Fikri A A Permanasari A A and Yanuhar U 2017 Pulsed electric field assisted extraction of cellulose from mendong fiber (Fimbristylis globulosa) and its characterization J. Nat. Fibers15 3 406-415

[7] Kim U JEom S H and Wada M 2010 Thermal decomposition of native cellulose : influence on crystallite sizePolym. Degrad. Stab.955 778-781 
[8] Mood S H Golfeshan A H Tabatabaei M Jouzani G S Najafi G H Gholami M and Ardjmand M 2013 Lignocellulosic biomass to bioethanol, a comprehensive review with a focus on pretreatment Renew. Sustain. Energy Rev.27 7793

[9] Tan Y T Ngoh G C and Chua A S M 2019 Effect of functional groups in acid constituent of deep eutectic solvent for extraction of reactive ligninBioresour. Technol.281359-366

[10] Donsi F Ferrari G and Pataro G 2010 Applications of pulsed electric field treatments for the enhancement of mass transfer from vegetable tissue Food Eng.Rev.22 109-130

[11] Putranto A W Argo B D and Wijana S 2014 Green pulsed electric field-assisted extraction method of total carotenoid carrot pulp using olive oil as solventIndones.Green Technol.J.31 1-9

[12] Izza N Dewi S R Putranto A W Yuneri D R and Dachi M Y S 2016 Ekstraksi senyawa fenol daun kenikir (Cosmos caudatus) dengan pulse electric field (PEF) J. Tek. Pertanian 172 91-96

[13] Dewi S R Sumarni N Izza N Putranto A W Susilo B 2019 Studi Variasi kuat medan listrik PEF dan Metode pengeringan bahan terhadap senyawa antioksidan ekstrak daun torbangun (Coleus amboinicus L.) J. Keteknikan Pertanian 71 9198

[14] Putranto A W Dewi S R Puspitasari Y and Nuriah F A 2018 Optimization of free radical scavenging capacity and $\mathrm{pH}$ of Hylocereus polyrhizus peel by response surface methodology in IOP Conference Series: Earth and Environmental Science $\mathbf{1 3 1}$ 